\title{
Determinants of home delivery in a semi urban setting of Nepal
}

\author{
Heera Tuladhar \\ Associate Professor,Department of Obs/Gyn, Nepal Medical College Teaching Hospital, \\ Jorpati, Kathmandu, Nepal.
}

\begin{abstract}
Aim: To study the effect of various determinants of home delivery in Nepal.

Methods: Prospective descriptive study among women who after being delivered at home were admitted in Nepal Medical College Teaching Hospital (NMCTH), a tertiary care hospital situated at suburban area of Kathmandu

Results: Of 114 women, majority were between the ages of 20-24 yrs. Most of the women were multipara (64\%). Majority had no formal education accounting for $68.4 \%$. Lasheta (Lama, Sherpa, Tamang) was the most common ethnic group. Most $(30.1 \%)$ of their spouses also were illiterate or had only primary level education. Majority of the husbands of the respondents were laborers (63.2\%). Regarding attendance of antenatal care (ANC); at least 84 (73.7\%) women had attended ANC once and half of the women had attended 4 more visits. Home delivery was planned by 67 (58.8\%) women; whereas only 47 (41.2\%) had chosen hospital delivery and delivered at home due to various reasons. Financial problem was the most common reason followed by ignorance and transportation problem. Among all the women, only 5.3\% were attended to by a professionally trained provider (doctor, nurse, and midwife). A disturbingly high proportion of women (87.6\%) were attended by an untrained family member, friend or neighbor, and $7 \%$ of women delivered completely unattended. Women were brought to the hospital by family member $59.6 \%$ other than husband and $8.8 \%$ were accompanied by neighbors/friends. Most of these women were brought with retained placenta, primary post partum hemorrhage.

Conclusion: In this study area, usage of the antenatal care was high, but the opportunity to deliver at hospital was not fully utilized. This study has highlighted some of the factors affecting the choice of place of delivery among mothers in a semi urban settlement in Nepal namely mothers educational level, husband's education and occupation, financial constraints, lack of transportation and ignorance. Majority of the deliveries took place at home and unsupervised by a skilled attendant thus aggravating the risk of the high perinatal and maternal morbidities and mortalities in the study area.
\end{abstract}

Key words: Home delivery, determinants, antenatal care, delivery attendance

\section{Introduction}

The place of delivery and its determinants have been on the research agenda for a long time. Birth is an event of great importance in family life. Advantages of home deliveries as perceived by public may be that mother feels more relaxed and secure in her own territory. Personalized care and caregivers are available in the home, and no unfamiliar people are present. Mother is able to avoid 'routine' medical interventions, such as intravenous lines, monitoring, and augmentation. Intervention rates are minimal, cost is also low. Home birth is viewed as a natural event, and part of the ongoing life experience of the family. Although pregnancy and delivery are, under healthy conditions, normal social and physiological processes, childbirth has become hospital centred in most industrialised countries. The assumption is that hospital based 
deliveries are safer for mother and child. In many developing countries, the majority of births occur at home without the help of a skilled assistant. Home deliveries in the absence of skilled professional attendants have been associated with adverse infant and maternal outcome ${ }^{1,2}$ However, home deliveries without a skilled attendant are chosen or occur for a variety of reasons, including long distances or difficult access to a birth facility, costs of services and perceived lack of quality of care in a health facility.

The immediate medical causes of maternal deaths are similar for women all over the world: postpartum hemorrhage, infection, toxemia, obstructed labor and septic abortions. An estimated $90 \%$ of maternal deaths could be avoided, if adequate care was provided. ${ }^{3}$ The millennium development goal no. 5 states that by 2015 the maternal mortality ratio should be reduced by three quarters. ${ }^{4}$ Attendance at antenatal clinics (ANCs) and receipt of professional delivery care have been associated with a reduction in maternal deaths. ${ }^{5,6}$ This low utilization of skilled attendants at delivery represents the great challenge to achieve the MDG's in the next six years.

Although the debate on the safety and women's right of choice to a home delivery vs. hospital delivery continues in the developed countries, an undesirable outcome of home delivery, such as high maternal and perinatal mortality, is documented in developing countries. In rural districts, the proportion of institutional deliveries is as low as $4 \% .^{7}$ Even in urban Kathmandu, a significant proportion of women, approximately $19 \%$, still deliver at home despite supposedly accessible institutional maternity services. ${ }^{8}$ A study in Tanzania showed that in home births conducted without a trained attendant, the perinatal mortality was three times higher than that for hospital or dispensary births with trained attendants. ${ }^{9}$ In Papua New Guinea, a high rate of obstetric complications was found amongst seemingly normal pregnancies delivering at home. ${ }^{10}$

In order to reduce maternal mortality, the Nepal government has increased its commitment to institutional deliveries. The National Safe Motherhood Program of Nepal emphasizes the provision of round the clock emergency obstetric service including transport and financial assistance. The program has recently implemented the scheme of financial and incentive for the mothers who choose institutional delivery. ${ }^{11}$

Issues of risk and vulnerability, such as lack of money, lack of transport, sudden onset of labour, short labour, staff attitudes, lack of privacy, tradition and cultures and the pattern of decision-making power within the household may be the key determinants of the place of delivery. It is important to identify the risk factors, which lead to home delivery and its adverse consequences. Hence this study reports the effect of various determinants of home delivery in a developing country like Nepal. The objective was to study whether socioeconomic factors, distance to maternity hospital, ethnicity, obstetric history and antenatal care received in present pregnancy are responsible for home delivery. The main outcome measures were social, educational and economic household details of pregnant women; pregnancy, antenatal care and obstetric details; plan of delivery; delivery attendant; the attendant bringing her to the hospital and reasons given for home delivery.

\section{Methods}

A prospective descriptive study was done from $15^{\text {th }}$ April, 2004 to $16^{\text {th }}$ October, 2008 total duration being $4 \frac{1}{2}$ years ( $1^{\text {st }}$ of Baisakh, 2061 B.S. to last of Asoj, 2065 B.S.) in Nepal Medical College Teaching Hospital, Jorpati, which is a 700 bedded tertiary care hospital situated at suburban area of Kathmandu.. This hospital covers mainly the suburban population and to some extent the urban population too. Both home and hospital delivery could be expected in the area.

The study population included all women who were admitted in the hospital within 6 weeks after delivering at home. All deliveries at home, including those deliveries on the way to hospital were defined as home delivery.

A questionnaire was developed to collect information about demographic characteristics, area of residence, educational status and occupation of husband and the woman, distance from hospital, obstetric history, use of antenatal care, plan of delivery, labor pain duration, type of delivery, fetal outcome, delivery attendant , reasons given for home delivery and complications encountered. The questionnaire was pre-tested was modified accordingly.

If the woman was not in a condition to communicate, the information was collected from her attendant. The purpose of the study was explained and informed verbal consent was obtained. All questionnaires were reviewed daily and forms with missing information and visible inconsistencies were completed as soon as possible by revisiting the mother for clarification.

\section{Results}

The number of women admitted after giving birth at home was 114 . Total number of delivery during the study period was 3473 . The proportion of home delivery was $3.2 \%$. The age of respondents ranged from 17 to 
42 years. Majority of the respondents were between the ages of 20-24 years (46.5\%). All of the respondents were married. Most of the women were multipara (64\%). Four $(3.6 \%)$ were preterm deliveries. Among the 73 multipara 45 had previous 1-4 home deliveries, 9 had already experienced complications like retained placenta, postpartum hemorrhage, still birth and neonatal death during previous home deliveries. But still they had home delivery this time also.

Majority had no formal education accounting for $68.4 \%$.

Lasheta (Lama, Sherpa, Tamang) was the most common ethnic group. Most of the women delivered at full term, whereas preterm delivery occurred in 4 (3.6\%). (Table 1).

Table 1. Socio-demographic characteristics of the study population $(n=114)$

\begin{tabular}{lcc}
\hline Characteristics & No. & $\%$ \\
\hline Age Group (years) & & \\
\hline $15-19$ & 18 & 15.8 \\
$20-24$ & 53 & 46.5 \\
$25-29$ & 27 & 23.7 \\
$30-34$ & 11 & 9.6 \\
$35-39$ & 3 & 2.6 \\
$40+$ & 2 & 1.8
\end{tabular}

\begin{tabular}{lrr}
\hline Parity & & \\
\hline 1 & 41 & 36.0 \\
$2-4$ & 70 & 61.4 \\
$5+$ & 3 & 2.6
\end{tabular}

\begin{tabular}{lrr}
\hline Occupation & & \\
\hline Housewife & 69 & 60.5 \\
Laborer & 35 & 30.7 \\
Farmer & 8 & 7.0 \\
Business & 2 & 1.8 \\
\hline
\end{tabular}

\begin{tabular}{lrr}
\hline Ethnic group & & \\
\hline Lama/Sherpa/Tamang & 58 & 50.9 \\
Brahmin/Chhetri & 26 & 22.8 \\
Magurali & 19 & 16.7 \\
Newar & 6 & 5.3 \\
Others & 5 & 4.3 \\
\hline
\end{tabular}

Educational status

\begin{tabular}{lrr}
\hline Illiterate & 78 & 68.4 \\
Primary & 19 & 16.7 \\
Secondary & 10 & 8.8 \\
Intermediate \& above & 7 & 6.1 \\
\hline
\end{tabular}

Most (30.1\%) of their spouses had no formal education as shown in table 2. Majority of the husbands of the respondents were laborers (63.2\%). Occupation of the spouse gives an idea of the low socio economic status in this semi urban setting where most of the population is engaged in carpet factory labor. (Table 2)

Eighty four (73.7\%) women had attended ANC at least once and half of the women had attended 4 and more visits. Majority came to hospital for ANC; more than half had been fully immunized with Tetenus Toxoid and taken iron supplementation. (Table 3)

\section{Table 2. Education and occupation of the} spouse

\begin{tabular}{lcc}
\hline Characteristics & No. & $\%$ \\
\hline Educational status & & \\
Illiterate & 34 & 30.1 \\
Primary & 47 & 41.1 \\
Secondary & 14 & 12.4 \\
Intermediate \& above & 19 & 16.4 \\
Occupation & & \\
Laborer & 72 & 63.2 \\
Service & 23 & 20.1 \\
Farmer & 12 & 10.6 \\
\hline
\end{tabular}

Table 3. Antenatal care (ANC)

\begin{tabular}{lcr} 
No. of visits & No. & $\%$ \\
\hline None & 30 & 26.3 \\
1 & 14 & 12.3 \\
$2-3$ & 13 & 11.4 \\
4 and more & 57 & 50.0 \\
Place of ANC & & \\
Hospital & 58 & 69.1 \\
Private clinic & 10 & 11.9 \\
Health post & 16 & 19.0 \\
Tetanus Toxoid (T.T.) immunization & \\
None & 36 & 31.6 \\
Partial & 14 & 12.3 \\
Full & 64 & 56.1 \\
Iron supplementation & & \\
None & 45 & 39.5 \\
Yes & 69 & 60.5 \\
\hline
\end{tabular}

Sixty seven (58.8\%) women had planned for home delivery whereas only $47(41.2 \%)$ had chosen hospital delivery and delivered at home due to various reasons. Financial problem was the most common reason followed by ignorance and transportation problem (fig 1). Most of the women lived near the hospital within 2 $\mathrm{km}$. Only $12 \%$ were brought from $>6 \mathrm{~km}$ distance. 


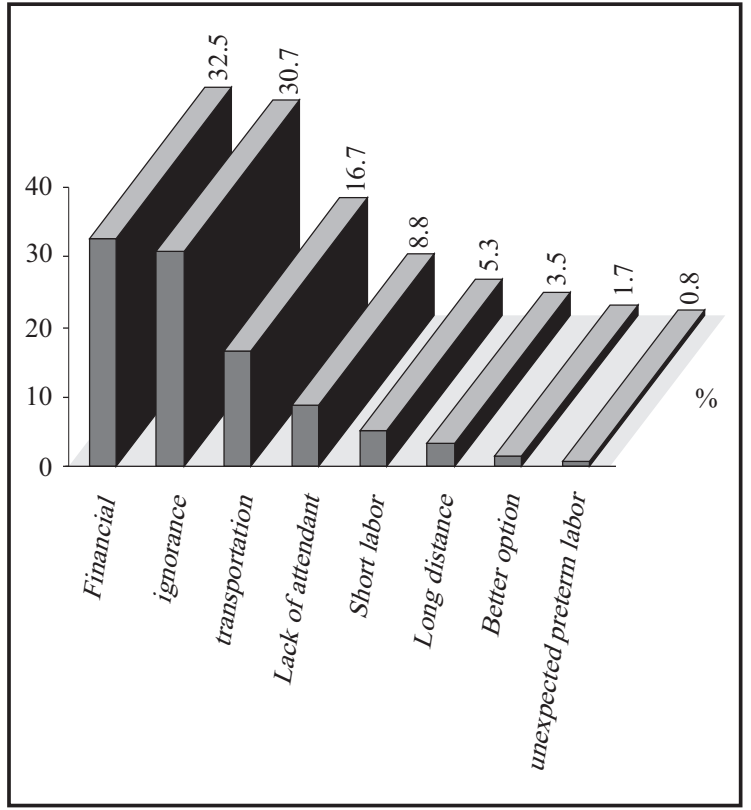

Figure 1: Reasons stated for home delivery

Most of the women (44.8\%) had normal duration of labor (6-12 hrs.) and 93\% had spontaneous term vaginal delivery. Among all women, only $5.3 \%$ were attended to by a professionally trained provider (doctor, nurse, and midwife). A disturbingly high proportion of women $(87.6 \%)$ were attended to by an untrained family member, friend or neighbor, and $7 \%$ of women delivered completely unattended $59.6 \%$ of the women were

Table 4. Labor and delivery details

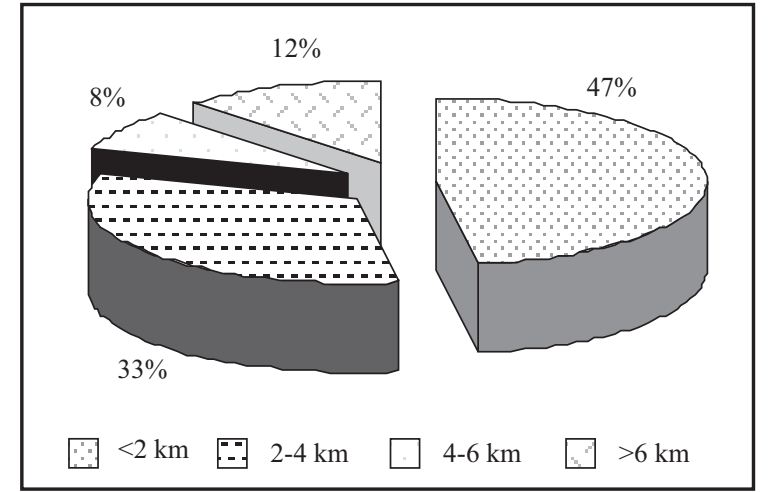

Figure 2: Distance from residence of women to the hospital

brought to the hospital by family member other than husband. $8.8 \%$ were accompanied by neighbors/friends only as there were nobody at home at the time of delivery.

\section{Discussion}

This study analyzed 114 women admitted in the hospital after home delivery in an attempt to look for the determinants of home delivery in the study population. This represents only that proportion who attended hospital due to some complications. Those women who did not attend hospital after home delivery could not be included in this study. However, the sample of the women interviewed may be representative of the semi urban population

\begin{tabular}{lrr}
\hline \multicolumn{1}{c}{ Details } & No. & $\%$ \\
\hline Duration of labor pain (hours) & & 9.6 \\
\hline Less than 2 hrs. & 11 & 34.2 \\
$2-6$ & 39 & 44.8 \\
$6-12$ & 13 & 11.4 \\
$>12$ & & \\
\hline Type of delivery & 106 & 93.0 \\
\hline Spontaneous term vaginal delivery & 3 & 2.6 \\
Breech delivery & 4 & 3.5 \\
Preterm & 1 & 0.9 \\
Twin & & 76.3 \\
\hline Delivery attended by & 87 & 6 \\
\hline Family member & 7 & 5.3 \\
Friend & 6 & 5.3 \\
Medical personnel & 6 & 7 \\
Untrained birth attendant & 8 & 12.3 \\
None & 14 & \\
Manipulations at home (abdominal pressure, pulling the & & \\
cord, tying heavy objects in the cord for traction etc.) & & \\
\hline
\end{tabular}


Table 5. Reasons for attending hospital

\begin{tabular}{lrr}
\hline Reasons & No. & $\%$ \\
\hline Retained placenta & 83 & 72.8 \\
Bleeding per vagina & 23 & 20.2 \\
Pain abdomen & 9 & 7.9 \\
Something coming out p/v & 9 & 7.9 \\
Unconsciousness & 8 & 7.0 \\
Fever & 7 & 6.0 \\
Swelling of limbs & 3 & 2.6 \\
\hline
\end{tabular}

\section{Sociodemographic profile of the respondents}

The majority of women belonged to age group 20-24 years which is similar in another study done by Sreeramareddy ${ }^{12}$ median age of the mothers was 24 years. The majority were Lama, Sherpa, Tamang, the predominant ethnic group of this semi urban area. In Nigeria, about two third of births occur at home according to the 2003 national demographic and health survey. ${ }^{13}$ In a study done by Bolam et al ${ }^{8} 272(81 \%)$ had an institutional delivery and $62(19 \%)$ delivered at home. low maternal educational level (no education, compared to those with higher education) and multiparity compared to primiparity) were significant risk factors for a home delivery. They conclude that poor education and multiparity rather than poverty per se increase the risk of a home delivery in Kathmandu.

In the study done by Wagle et $\mathrm{al}^{14}$ the ethnic groups Tamang/Magar had 2.5 times higher risk of delivering at home when compared with Brahmin, Chhetri, Newar. There were substantial variations between ethnic groups with respect to place of delivery $(\mathrm{P}<0.0001)$ in a study in Tanzania. ${ }^{15}$

In similar study in Tanzania ${ }^{16}$ almost half (49.4\%) of the respondents had never been to school.

Seventy $(68.4 \%)$ respondents were illiterate and only seven $(6.1 \%)$ had education of high school and above as compared to $38.8 \%$ and $13.7 \%$ in study done at western Nepal. ${ }^{12}$ The utilization of a hospital/clinic instead of birth at home is higher among women with secondary or higher level of education in rural Bangladesh. ${ }^{17}$

Mothers with primary and higher education were more likely to deliver at a health facility in Tanzania (RR 1.30, 95\% CI 1.23-1.38). ${ }^{15}$ In Mrisho et al's study, maternal and paternal education, were statistically significant predictors of the choice of public versus private facility delivery. ${ }^{18}$

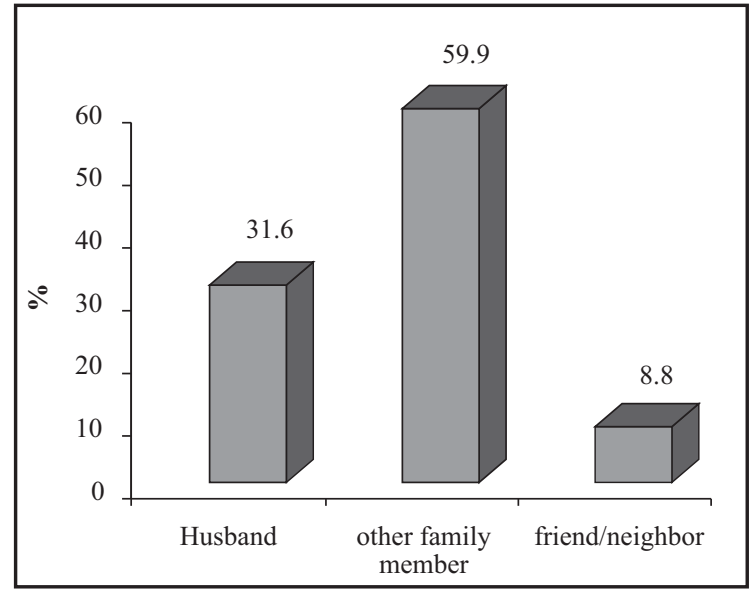

Figure 3: Attendant on arrival at hospital

The lower level of mother's education, mother's occupation other than office work, lower yearly income, lower amenity score status and the long distance to maternity hospital with facilities for caesarean section, are all statistically significantly associated with a higher prevalence proportion of home delivery. Lower the economic status of the women more likely that she would not go into hospital for delivery. The secondary and lower level of the husband's education and occupation other than office work were also found to be statistically significantly associated with home delivery. Living farther than one hour away is 8 times and low amenity score status was 4 times more likely to lead to home delivery. Mother's education lower than primary, not having antenatal care and multiparity were also associated with a high prevalence proportion of home delivery. Ethnicity (classified in 3 groups) was not statistically significant associated with place of delivery when adjusted with amenity score status. ${ }^{14}$

The education and occupation of spouse gives rough idea about low socioeconomic status of majority of the women The findings are similar in many developing countries although we can see the opposite in developed countries like the Netherlands. ${ }^{19}$

The Dutch researchers reported that compared to the higher socio-economic status group, there was an increased risk of hospital delivery in the lower socioeconomic group in the Netherlands. Though it can be easily appreciated that home deliveries in Nepal are in no way comparable to Dutch home deliveries with a trained midwife and immediate access to emergency transport

\section{Antenatal care attendance}

Out of the 114 respondents $26.3 \%$ comparable to $30.4 \%{ }^{12}$ and $10 \%^{20}$ had not gone for any antenatal visit and $50 \%$ had at least four antenatal visits as recommended 
by the National Safe Motherhood Program of Nepal. Antenatal care attendance was high with $73.7 \%$ attending at least one visit, but is still a lower rate compared to $96 \%$ in $\mathrm{Uganda}^{21}$ and $90 \%$ in Kenyan study ${ }^{20}$ visited ANC at least once. $56.1 \%$ received two doses of tetanus toxoid as recommended by the National Safe Motherhood Program, the rate is 35.8\% in Sreeramareddy's study. ${ }^{12}$ It is worth noting that adequate ANC attendance during pregnancy did not significantly influence hospital delivery based on the findings of this study. Other socio-cultural factors, cost of care may account for the observed high rate of home deliveries despite adequate ANC attendance.

Mothers who did not seek antenatal care during pregnancy were 4.5 times more likely to choose delivery at home. ${ }^{14}$ The high ANC attendance in this area is encouraging, and is similar to a report for the whole of Kenya $(88 \%)$. ${ }^{22}$ Women who had more than 4 ANC visits were more likely to deliver with a skilled attendant than those with fewer visits as reported by Rose et al. ${ }^{16}$

\section{Past obstetric performance of the respondents}

Sixty four percent of the women in this study were multipara. Among the 73 multipara 45 had previous 14 home deliveries, 9 had already experienced complications like retained placenta, postpartum hemorrhage, still birth and neonatal death during previous home deliveries. Of the 173 multiparous women $148(85.5 \%)$ had delivered at home at least once before. Seven mothers reported of having had a still birth $(2.9 \%), 16$ a neonatal death $(6.7 \%)$ and four a postneonatal death $(1.7 \%)$ after their previous home deliveries in another study done in Nepal. ${ }^{12}$

Previous unfortunate experiences in hospital, quicker childbirth in the multipara or having had an uncomplicated first home delivery might explain why some of the multipara chose to deliver at home.

\section{Attendance at delivery}

This study revealed that most of the deliveries (87.6\%) were not supervised by skilled personnel and $7 \%$ of women delivered completely unattended. This finding was similar to other studies. Among all women, only $5.3 \%$ were attended to by a professionally trained provider (doctor, nurse, midwife) comparable to $6.3 \%$ deliveries attended by skilled personnel $53.3 \%$ deliveries attended by neighbors, $21.3 \%$ attended by family members and $15.8 \%$ gave birth alone. Ninty one percent of women delivering at home were attended only by relatives and $7 \%$ by assistant nurse midwifes in Wagle's study. ${ }^{14}$ In study of Anna et al ${ }^{20}$ only $17 \%$ were attended to by a professionally trained provider (doctor, nurse, midwife, or clinical officer. Twenty nine percent were attended to by an untrained family member, friend or neighbor, and $18 \%$ of women delivered completely unattended. The situation is slightly better as $50.1 \%$ were assisted by untrained relatives or friends while $46.3 \%$ were assisted by Traditional Birth Attendants (TBA's) and 3.6\% were assisted by skilled midwives in Tanzanian study. ${ }^{16}$

Twenty seven percent of the deliveries were unattended, female relatives attended $60 \%$ of home deliveries and the husband attended $12 \%$ of the home deliveries in study by Garner. ${ }^{23}$

It was surprising to see the high proportion of women who gave birth without any assistance. The lack of any attendant makes it difficult to seek assistance in the event of life-threatening complications. Women should be strongly encouraged to deliver with assistance.

\section{Reasons for delivering at home}

In our study 67 (58.8\%) women had planned for home delivery whereas only $47(41.2 \%)$ as compared to $41.7 \%{ }^{12}$ had chosen hospital delivery and delivered at home due to various reasons. The common reasons cited for unplanned home deliveries were 'precipitate labor', 'lack of transportation' and 'lack of escort' during labor. 'Financial problems at home' and 'worries about cost of care in the hospital' , 'distance of the hospital' , 'fear about hospital' and 'family members' preference for home delivery' were also mentioned as the reasons for delivering at home. In a study by Wilson et al ${ }^{24}$ the identified reasons for non utilization of obstetric services include: financial constraints, lack of awareness of maternity waiting homes, no perceived need for such services, preference for home delivery because it is much less expensive and etc.

Anna et $\mathrm{al}^{20}$ reported $80 \%$ delivered in their own house. The most frequent reason for not attending a health facility for delivery was lack of means of transport, in particular at night (49\%). Other important barriers were fast progression of labor (47\%), and expense (28\%). Fourteen percent of women did not think facility attendance was necessary; reasons given for this included previous uneventful home delivery, preferred home deliveries, or had made arrangements with TBAs or another person to attend the delivery. Wagle ${ }^{14}$ concluded the lower the economic status of the mother, the more likely that she would not go into hospital for delivery. The secondary and lower level of the husband's education and occupation other than office work were also found to be statistically significantly associated with home delivery. Living farther than one hour away is 8 times and low amenity score status was 
4 times more likely to lead to home delivery. Education lower than primary were associated with not having antenatal care and multiparity. ${ }^{14}$ A study on use of obstetric services in rural Nigeria shows that educational level, occupation of women, religion and occupation of the spouse were found to be the most consistent associated factors with the use of health facilities for delivery. ${ }^{25}$

Studies carried out in Kathmandu and its surrounding areas have reported socioeconomic status and multiparity as strong predictors of the place of delivery. Low socio-economic status has been found as a predictor for place of delivery. Of home deliverers, over half were unplanned due to precipitate labour or lack of transport. ${ }^{8}$ Other studies also have implicated different socio-economic factors as determinants of place of delivery. In a Nigerian study, $41 \%$ of the mothers who did not deliver in hospital explained that they could not afford the hospital bill, and $31 \%$ said they had inadequate transportation possibilities. ${ }^{26}$ In developed countries, women may prefer to give birth at home for dimensions of experience unavailable in hospital. Indeed, it was reported from New Zealand, that mothers who choose a home delivery do so for reasons of control, continuity and the familiarity of home. ${ }^{27}$

\section{Distance from hospital}

A study conducted by Hodgkin ${ }^{28}$ reported that $52 \%$ of deliveries occurred at home and the most significant predictors of choosing an informal delivery setting (home) are the household's distance from the nearest maternity centre greater the distance to a health facility with maternity beds, the less likely women would deliver at a health facility ( $\mathrm{p} 0.01$ ).

Wagle ${ }^{14}$ also studied the distance to the maternity hospital as having a causal role for place of delivery. Long distance from the maternity hospital was found to be significantly associated with home delivery and a linear trend could be seen. In Kenya, the most significant predictors of choosing home delivery (an informal delivery setting) are the distance from the household to the nearest maternity bed. ${ }^{28}$ In Carolyn 's study ${ }^{21}$ of women who delivered at home: $34 \%$ (15) stated that this was due to financial limitations, $23 \%$ (10) due to transport limitations, and $27 \%$ (12) due to 'other reasons' which were most commonly stated as to be due to the delivery occurring too quickly or too late at night to attend the facility of choice. Of the women who reported that financial and transport limitations were the most important factor in where they delivered, $40 \%$ and $37 \%$ respectively delivered at home with no trained assistance. The results suggest that travel time is an important barrier to access.
But in present study, most of the women lived within $2 \mathrm{~km}$ from the hospital and only $12.2 \%$ came from $>6 \mathrm{~km}$ distance. The findings of our study suggest that easy access to maternity services may not be enough to ensure the use of such services. Lack of utilization may be influenced by income, education and cultural beliefs. Financial constraints may be the main reason for not using these facilities.

\section{Conclusion}

This study has highlighted some of the factors affecting the choice of place of delivery among mothers in a semi urban settlement in Nepal namely mothers educational level, husband's education and occupation, financial constraints, lack of transportation and ignorance. Majority of the deliveries took place at home and unsupervised by a skilled attendant thus aggravating the risk of the high perinatal and maternal morbidities and mortalities in the study area.

Girl child education at least up to secondary school level, training of traditional birth attendants and sustainable poverty alleviation programs through income generating activities appear to be viable options and strategies to ensure institutional deliveries, skilled attendant at birth and consequently safe motherhood in the study area.

\section{References}

1. Koblinsky MA, Campbell O, Heichelheim J: Organizing delivery care: what works for safe motherhood? Bull World Health Organ 1999, 77:399-406.

2. De Brouwere V, Tonglet R, Van Lerberghe W: Strategies for reducing maternal mortality in developing countries: what can we learn from the history of the industrialized West? Trop Med Int Health 1998, 3:771-782.

3. Faundes A, Rosenfield A, Pinotti JA. Maternity care in developing countries: relevance of new technological advances. Int J Gynecol Obstet. 1988;24:103-109.

4. WHO. World health report 2005. Make every mother and child count. Geneva: WHO, 2005.

5. Magadi M, Madise N, Diamond I: Factors associated with unfavourable birth outcomes in Kenya. J Biosoc Sci 2001, 33:199-225.

6. UNICEF Eastern and Southern Africa Regional Office: Maternal Mortality Reduction Strategy. 2003.

7. Ministry of Health, Family Health Division. Maternal mortality and morbidity study. Kathmandu. 1998. 
8. Bolam A, Manandhar DS, Shrestha P, Ellis M, Malla K, Costello AM. Factors affecting home delivery in the Kathmandu valley. Health Policy Plann. 1998;13:152-158.

9. Walraven GEL, Mkanje RJB, Roosemalen J, Van Dongen PWJ, Dolmans WMV Perinatal mortality on homebirths in rural Tanzania. Eur J Obstet Gynecol Reprod Biol. 1995;58:131-134.

10. Garber P, Lai D, Baea M. Childbirth in rural area: maternal death, village deliveries and obstetric service use. PNG Med J. 1994;37:166-172.

11. Ministry of Health, His Majesty Government, Nepal. Annual Health Report-2004.

12. Sreeramareddy CT, Joshi HS, Sreekumaran BV, Giri S, Chuni N. Home delivery and newborn care practices among urban women in western Nepal: a questionnaire survey. BMC Pregnancy Childbirth 2006; 6: 27

13. Nigeria demographic and health survey 2003: key findings. National Population Commission, Abuja and ORC Macro, Maryland 2004; 2-8

14. Wagle R R, Svend S, and Nielsen B B. Socioeconomic and physical distance to the maternity hospital as predictors for place of delivery: an observation study from Nepal BMC Pregnancy Childbirth. 2004; 4: 8 .

15. Mrisho M, Schellenberg JA, Mushi AK, Obrist B, Mshinda H, Tanner M, Schellenberg D. Factors affecting home delivery in rural Tanzania. Trop Med Int Health 2007 ; 12:862-72

16. Rose NM , Japhet ZK, Melkzedeck TL et al. Use pattern of maternal health services and determinants of skilled care during delivery in Southern Tanzania: implications for achievement of MDG-5 targets BMC Pregnancy Childbirth. 2007; 7:29.

17. Islam MA, Chowdhury RI, Akhter HH. Complications during pregnancy, delivery, and postnatal stages and place of delivery in rural Bangladesh. Health Care Women Int 2006 ;27:80721
18. Thind A, Mohani A, Banerjee K, Hagigi F. Where to deliver? Analysis of choice of delivery location from a national survey in India. BMC Public Health 2008 24;8:29

19. Herngreen WP, Reerink JD, van Noord-Zaadstra BM, Verloove-Vanhoric SP, Ruys JHR. Relationship between socio-economic status and differences in health care utilization in pregnancy, delivery and puerperium. (Article in Dutch with English Abstract). Ned Tijdschr Genneskd. 1993;137:1007-1012.

20. Anna ME, Hanneke MB, Frank O et al. Use of antenatal services and delivery care among women in rural western Kenya: a community based survey Reproductive Health 2006, 3:2

21. Carolyn JT, Moses K,Linda M. Use of antenatal services and delivery care in Entebbe, Uganda: a community survey. BMC Pregnancy Childbirth. 2007; 7: 23

22. Central Bureau of Statistics, Ministry of H, O. R. C. Macro: Kenya Demographic and Health Survey 2003. Calverton, Maryland, USA; 2004.

23. Garner P, Lai D, Baea M. Childbirth in rural areas: maternal deaths, village deliveries and obstetric service use. P N G Med J. 1994 ;37:166-72.

24. Wilson JB, Collison AHK, Richardson D et al The maternity waiting home concept: the Nsawam Ghana experience. Int J Gynecol Obstet 1997; 59 (suppl. 2): S165-S172

25. Nwakoby BN. Use of obstetric services in rural Nigeria. J Reprod Soc Hlth 1994; 114: 132-136

26. Fajemilehin BR. Factors influencing high rate of 'born before arrival' babies in Nigeria-a case control study in Ogbomsho. Int J Nurs Stud. 1991;28:13-18

27. Abel S, Kearns RA. Birth places: a geographical perspective on planned home birth in New Zealand. Soc Sci Med. 1991;33:825-834..)

28. Hodgkin D. Household characteristics affecting where mothers deliver in rural Kenya.Health Econ 1996; 5:333-40. 